were due to the effects of brachytherapy and not to the use of metallic clips or EBRT.

In conclusion, although surgery remains the first choice to treat ROLC, a considerable number of patients are inoperable. EBRT is an alternative, but is hampered since the ROLC is effectively invisible. We report that the use of metallic clips placed during bronchoscopy can make ROLC visible for the radiation oncologist. The clips appear to be safe, well tolerated and removable in inoperable patients with ROLC who are candidates for EBRT. In the future, this technique could facilitate EBRT or even stereotactical beam radiotherapy in patients with ROLC. Prospective studies further investigating this technique are warranted.

T. Malfait*, M. van Eijkeren", J.P. van Meerbeeck ${ }^{\top}$ and K.G. Tournoy*

*Dept of Respiratory Medicine, "Dept of Radiation Oncology, Ghent University Hospital, and "Long Oncologisch Netwerk Gent (LONG), Ghent, Belgium.

Correspondence: T. Malfait, Dept of Respiratory Medicine, Ghent University Hospital, De Pintelaan 185, Ghent 9000, Belgium. E-mail: thomas.malfait@uzgent.be

Statement of Interest: None declared.

\section{REFERENCES}

1 Martini N, Melamed MR. Occult carcinomas of the lung. Ann Thorac Surg 1980; 30: 215-223.

2 Cortese DA, Pairolero PC, Bergstralh EJ, et al. Roentogenographically occult lung cancer. A ten-year experience. J Thorac Cardiovasc Surg 1983; 86: 373-380.
3 Kennedy T, McWillians A, Edell E, et al. Bronchial intraepithelial neoplasia/early central airways lung cancer. ACCP evidencebased clinical practice guidelines (2nd edition). Chest 2007; 132: 221S-233S.

4 Sutedja TG, van Boxem AJ, Postmus PE. The curative potential of intraluminal bronchoscopic treatment for early-stage non-smallcell lung cancer. Clin Lung Cancer 2001; 2: 264-270.

5 Vonk-Noordegraaf A, Postmus PE, Sutedja TG. Bronchoscopic treatment of patients with intraluminal microinvasive radiographically occult lung cancer not eligible for surgical resection: a follow-up study. Lung Cancer 2003; 39: 49-53.

6 Saito M, Yokoyama A, Kurita Y, et al. Treatment of roentogenographically occult endobronchial carcinoma with external beam radiotherapy and intraluminal low dose rate brachytherapy: second report. Int J Radiation Oncology Biol Physic 2000; 47: 673-680.

7 Fuwa N, Ito Y, Matsumoto A, et al. The treatment results of 40 patients with localized endobronchial cancer with external beam irradiation and intraluminal irradiation using low dose rate ${ }^{192}$ Ir thin wires with a new catheter. Radiotherap Oncol 2000; 56: 189-195.

8 Fuwa N, Kodaira T, Tachibana H, et al. Long-term observation of 64 patients with roentgenographically occult lung cancer treated with external irradiation and intraluminal irradiation using lowdose-rate iridium. Jpn J Clin Oncol 2008; 38: 581-588.

9 Fuwa N, Matsumoto A, Kamata M, et al. External irradiation and intraluminal irradiation using middle-dose-rate iridium in patients with roentgenographically occult lung cancer. Int $J$ Radiat Oncol Biol Phys 2001; 49: 965-971.

10 Furuta M, Tsukiyama I, Ohno T, et al. Radiation therapy for roentogenographically occult lung cancer by external beam irradiation and endobronchial high dose rate brachytherapy. Lung Cancer 1999; 25: 183-189.

11 Silvestri GA, Gould MK, Margolis ML, et al. Noninvasive staging of non-small cell lung: ACCP evidenced-based clinical practice guidlines ( $2^{\text {nd }}$ edition). Chest 2007; 132: 178S-201S.

DOI: $10.1183 / 09031936.00200209$

\title{
lloprost-induced thrombocytopenia: a case proven by rechallenge
}

\section{To the Editors:}

A 63-yr-old female underwent aortic and mitral valve replacement surgery (ATS 18 and $29 \mathrm{~mm}$, respectively; ATS Medical, Inc., Minneapolis, MN, USA) for aortic stenosis and mitral incompetence in August 2009. Pre-operatively, she was in New York Heart Association class III and exhibited comorbid hypertension, obstructive sleep apnoea (managed with nighttime continuous positive airway pressure), obesity (body mass index of $42 \mathrm{~kg} \cdot \mathrm{m}^{-2}$ ) and hypercholesterolaemia. Pre-operative right and left heart catheter investigation demonstrated a normal left ventricular ejection fraction, mean aortic valve gradient of $42 \mathrm{mmHg}$ (normal 0-10 $\mathrm{mmHg}$ ), valve opening area of $0.7 \mathrm{~cm}^{2}$ (normal $>2 \mathrm{~cm}^{2}$ ), mean pulmonary arterial pressure of $48 \mathrm{mmHg}$ (normal $12-16 \mathrm{mmHg}$ ), pulmonary vascular resistance of $225 \mathrm{dyn} \cdot \mathrm{s} \cdot \mathrm{cm}^{-5}$ (normal 100-200 dyn $\cdot \mathrm{s} \cdot \mathrm{cm}^{-5}$ ), pulmonary capillary wedge pressure of $34 \mathrm{mmHg}$ and cardiac output of $4.97 \mathrm{~L} \cdot \mathrm{min}^{-1}$. Her medication included an angiotensinconverting enzyme inhibitor, diuretics and aspirin.

Her post-operative course was complicated by a sternal wound infection, mediastinitis, pneumonia and renal failure requiring continuous high-flow haemodiafiltration. On the 14th postoperative day, she developed right heart failure (central venous pressure (CVP) of $25 \mathrm{mmHg}$, mean arterial pressure $\left(\bar{P}_{\mathrm{a}}\right)$ of $60 \mathrm{mmHg}$ and severely impaired right ventricular function on echocardiography) due to sepsis- and pneumoniarelated exacerbation of her initially mild post-capillary pulmonary hypertension. She required mechanical ventilation in a spontaneously breathing mode and circulatory support with noradrenalin and dobutamine. Treatment with inhaled iloprost (Ilomedin $\mathbb{R}$; Bayer Schering Pharma, Berlin, Germany) was commenced in order to reduce pulmonary arterial pressures and right ventricular work. A total of $10 \mu \mathrm{g}$ iloprost 
were administered by nebulisation via a Micro-Cirrus ${ }^{\mathrm{TM}}$ device (Intersurgical, Wokingham, UK) every $3 \mathrm{~h}\left(80 \mu \mathrm{g} \cdot 24 \mathrm{~h}^{-1}\right)$, with a resulting increase in $\bar{P}_{\text {a }}$ from 60 to $80 \mathrm{mmHg}$ and reductions in serum lactate level from 10 to $1.3 \mathrm{mM}$ and CVP from 25 to $16 \mathrm{mmHg}$ during the subsequent $48 \mathrm{~h}$. This treatment with iloprost was off-label in terms of indication and mode of application. On day 1 of iloprost treatment, the patient's platelet count was $295 \times 10^{9}$ cells $\cdot \mathrm{L}^{-1}$, but fell continuously to $25 \times 10^{9}$ cells $\cdot L^{-1}$ on day 6 , when iloprost was withdrawn (fig. 1). Concomitant medication included vancomycin, heparin, dobutamine, noradrenalin, fluconazole, ceftriaxone, remifentanil, haloperidol and morphine. Although screening for anti-heparin platelet factor 4 antibodies was negative, heparin was discontinued. The platelet count began to recover as soon as iloprost was withdrawn. Falling $\bar{P}_{\text {a }}$ and rising CVP and serum lactate levels, however, prompted recommencement of iloprost $\left(120 \mu \mathrm{g} \cdot 24 \mathrm{~h}^{-1}\right)$. The platelet count fell again on this rechallenge, and iloprost was again withdrawn. Heparin, however, was recommenced and platelet counts continued to recover (fig. 1). There was no bleeding and platelet transfusion was not required. Disseminated intravascular coagulation was excluded by the presence of normal fibrinogen and D-dimer levels. Pseudothrombocytopenia was excluded by the absence of platelet clumps in the blood film. Additionally, in the peripheral blood, there was no evidence of global bone marrow suppression or thrombotic microangiopathy.

The differential diagnosis of the thrombocytopenia included heparin-induced thrombocytopenia type II, disseminated intravascular coagulation, haemofiltration-induced thrombocytopenia, pseudothrombocytopenia, and iloprost-, vancomycin- or dobutamine-induced thrombocytopenia. The first three causes could be excluded on the basis of normal findings in their respective diagnostic tests, and there was no temporal relationship between either vancomycin or dobutamine exposure (both previously described to be associated with thrombocytopenia $[1,2])$ and thrombocytopenia. Thus thrombocytopenia caused by iloprost was the likeliest cause.

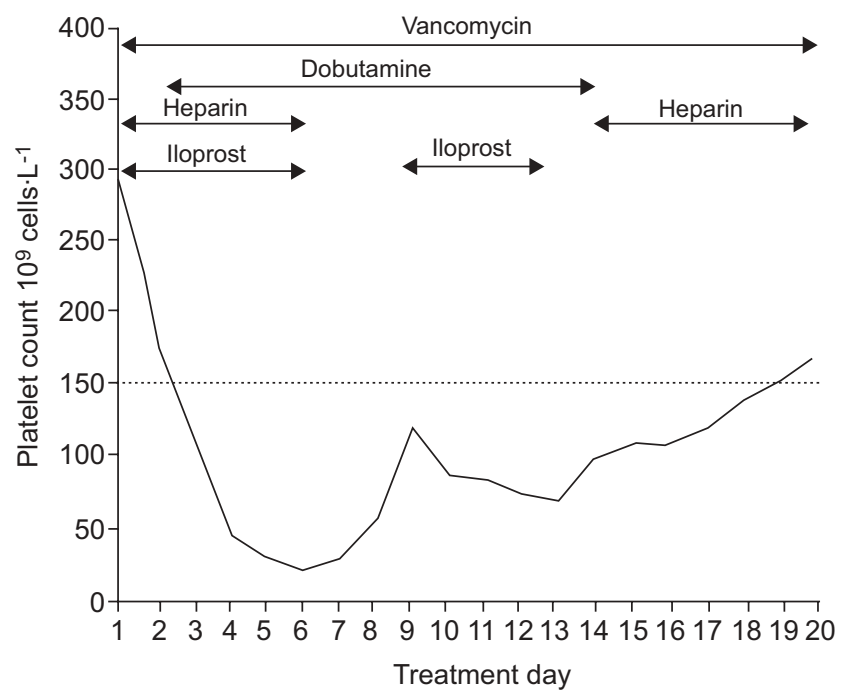

FIGURE 1. Platelet count over time during iloprost treatment (…...... lower limit of normal platelet count). Concomitant therapy with potential thrombocytopenic agents is shown.
In 1998, GEORGE et al. [3] established the criteria for the diagnosis of drug-induced thrombocytopenia. These are: 1) the candidate drug preceded thrombocytopenia and recovery from the thrombocytopenia was complete and sustained after the drug was discontinued; 2 ) the candidate drug was the only drug used prior to the onset of thrombocytopenia or other drugs were continued or reintroduced following discontinuation of the candidate drug with a sustained normal platelet count; 3) other aetiologies of thrombocytopenia were excluded; and 4) re-exposure to the candidate drug resulted in recurrent thrombocytopenia. In the present case, iloprost was the only medication that fulfilled all four criteria and can thus be classified as a definite cause of the drug-induced thrombocytopenia.

Iloprost (Ilomedin ${ }$ or Ventavis ${ }^{\circledR}$; Bayer Schering Pharma) is a synthetic prostacyclin analogue used in the treatment of pulmonary arterial hypertension. Commonly reported sideeffects of iloprost are hypotension, cough, headache, gastrointestinal disturbance, chest pain, dyspnoea, bronchospasm and wheezing [4]. Although iloprost is a potent platelet inhibitor, thrombocytopenia has not previously been reported in the medical literature. Post-marketing surveillance data regarding Ventavis ${ }$ revealed cases of gingival bleeding and epistaxis within 1 month of commencing therapy [5]; however there are no data on platelet count or the frequency of this complication. Pharmacovigilance database enquiry (Swissmedic national database on spontaneous reports of suspected adverse drug reactions and World Health Organization VigiBase ${ }^{\mathrm{TM}}$ [6] accessed in December 2009) revealed five cases of possible iloprost-induced thrombocytopenia in four countries during 2004-2009. In two cases, the route of administration was inhaled, in two intravenous and in one unknown. In three cases, recovery of platelet counts and no attributable deaths were reported. Epoprostenol, another prostacyclin analogue, however, has been associated with the development of thrombocytopenia [7].

The exact mechanism of this iloprost-induced thrombocytopenia remains unclear, but the rapidity of onset would be compatible with antibody-mediated platelet destruction. It is possible that iloprost or its metabolites dinoriloprost and tetranoriloprost form complexes with pre-existing immunoglobulin (Ig) molecules and that these then bind to prostacyclin receptors on platelets, thereby causing Fc-mediated platelet activation and subsequent destruction through elimination via the reticulo-endothelial system, similar to the mechanism whereby vancomycin causes platelet destruction [1]. The slower recovery of the platelet count following the second exposure to iloprost seen in the case described here would support this hypothesis. Confirmation of this mechanism would require detection of iloprost-dependent $\operatorname{IgM}$ and/or platelet-reactive IgG in serum.

\section{A.B. Taegtmeyer*, C. Zettler ${ }^{\#}$, M. Siegemund ${ }^{\#}$, D.A. Tsakiris ${ }^{\Uparrow}$, A.E. Rätz Bravo ${ }^{+}$, H. Pargger ${ }^{\#}$, S. Kraehenbuehl* and M. Haschke*}

*Divisions of Clinical Pharmacology and Toxicology, and 'Hematology, ${ }^{+}$Regional Pharmacovigilance Centre Basle, and \#Operative Intensive Care Unit, University Hospital Basle, Basle, Switzerland. 
Correspondence: M. Haschke, Division of Clinical Pharmacology and Toxicology, University Hospital Basel, Petersgraben 4, CH-4031 Basel, Switzerland. E-mail: HaschkeM@uhbs.ch

Statement of Interest: None declared.

\section{REFERENCES}

1 Von Drygalski A, Curtis BR, Bougie DW, et al. Vancomycininduced immune thrombocytopenia. N Engl J Med 2007; 356: 904-910.

2 Documed. Product information dobutamine injection. Arzbeunuttel Kompendium der Schweiz. [Swiss Compendium of Therapeutic Drugs.] www.documed.ch Date last updated: 2005. Date last accessed: December 1, 2009.
3 George JN, Raskob GE, Shah SR, et al. Drug-induced thrombocytopenia: a systematic review of published case reports. Ann Int Med 1998; 129: 886-890.

4 Lee SH, Rubin LJ. Current treatment strategies for pulmonary arterial hypertension. J Intern Med 2005; 258: 199-215.

5 US Food and Drug Administration. Ventavis (iloprost) inhalation solution September 2008. MedWatch FDA Safety Information and Adverse Event Reporting Program. Date last updated: June 19, 2009. Date last accessed: December 1, 2009.

6 Uppsala Monitoring Centre World Health Organization collaborating Centre for International Drug Monitoring. VigiBase ${ }^{\mathrm{TM}}$ Services. www.umc-products.com Date last accessed: December 1, 2009.

7 Chin KM, Channick RN, de Lemos JA, et al. Hemodynamics and epoprostenol use are associated with thrombocytopenia in pulmonary arterial hypertension. Chest 2009; 135: 130-136.

\section{Azithromycin treatment failure in macrolide-resistant Mycoplasma pneumoniae pneumonia}

\section{To the Editors:}

Mycoplasma pneumoniae is one of the most common bacterial causes of community-acquired pneumonia (CAP) [1]. Although most cases are mild, life-threatening diseases are also reported [2]. Clinical guidelines have recommended macrolides for treatment of community-acquired infection to target atypical organisms including M. pneumoniae [3] but there have been an increasing number of reports of macrolideresistant $M$. pneumoniae isolated from clinical specimens [4]. Although there are studies suggesting poorer responses to macrolide in patients infected with macrolide-resistant strains, these are mainly limited to patients with mild disease. Here, we report a case of CAP due to macrolide-resistant M. pneumoniae with poor response to azithromycin but rapid resolution after tigecycline.

In October 2009, a 24-yr-old female was admitted to our hospital with a 4-day history of fever, sore throat, cough and myalgia, associated with nausea, vomitting and diarrhoea. 2 months before admission, she was hospitalised for acute pyelonephritis due to Escherichia coli. Otherwise, her past health was unremarkable. She traveled to Xi'an, China, for 7 days and returned to Hong Kong 10 days before the onset of symptoms. While in Xi'an, she stayed with her father, who had an episode of suspected respiratory tract infection, presenting with cough and sputum.

2 days before admission, she attended the accident and emergency department of a regional hospital in Hong Kong SAR (China). A chest radiograph showed right middle zone consolidation (fig. 1a). Her temperature was $39.4^{\circ} \mathrm{C}$, blood pressure was $101 / 57 \mathrm{mmHg}$, pulse was 111 beats $\cdot \mathrm{min}^{-1}$, respiratory rate was 16 breaths $\cdot \mathrm{min}^{-1}$ and oxygen saturation was $98 \%$ while breathing ambient air. She was discharged with amoxicillin-clavulanate (1,000 $\mathrm{mg}$ twice daily) and paracetamol. Because of persistent symptoms 1 day before admission, azithromycin (500 mg once daily) and oseltamivir (75 mg twice daily) were added as treatment for CAP. RT-PCR of nasopharyngeal aspirate for influenza, collected 1 day before
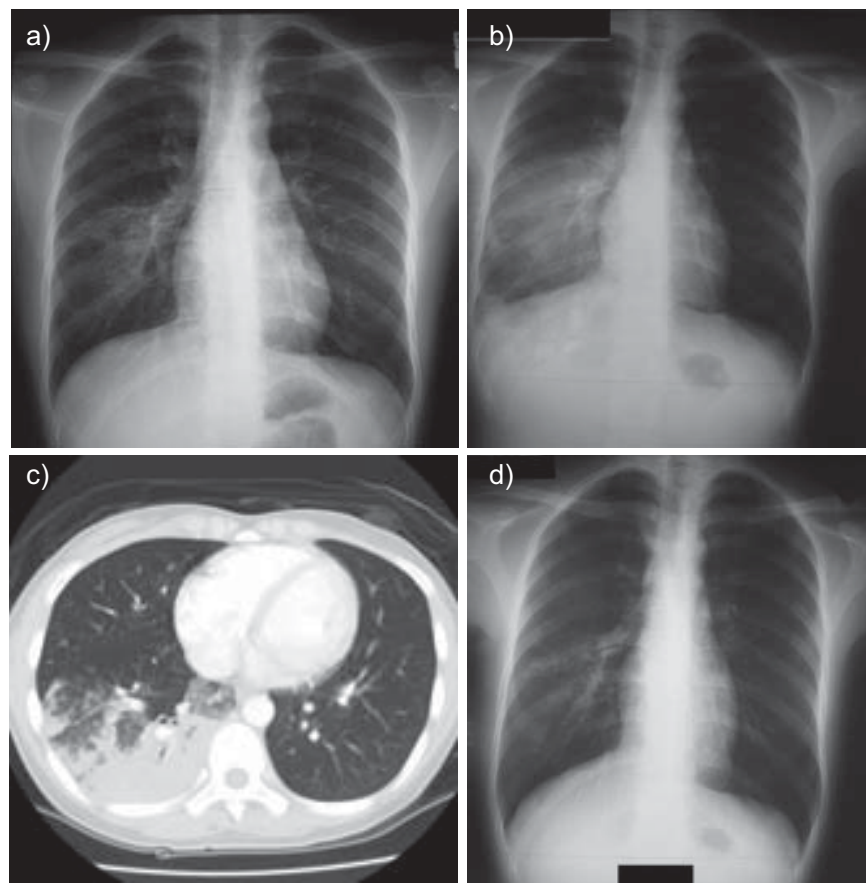

FIGURE 1. Radiographical findings. a) Chest radiograph taken 2 days before admission, showing right middle zone consolidation. b) Chest radiograph on 7th day of hospitalisation, showing progression of consolidation. c) Computed tomography on 7th day of hospitalisation, showing right lower lobe consolidation with ground-glass opacification. d) Chest radiograph on 17th day of hospitalisation, showing resolution of consolidation. 